\title{
O Campo como Laboratório: Relevância das Viagens Didáticas na Formação do Profissional em Lazer e Turismo - Estudo de Meio em Curitiba/PR
}

\author{
Flávia Ulian \\ Faculdade de Tecnologia Victor Civita - Fatec/Tatuapé \\ * Autora para correspondência: flavia.ulian@fatec.sp.gov.br
}

\begin{abstract}
RESUMO
O relato apresenta as vantagens de se utilizar o trabalho de campo como prática pedagógica nos cursos de graduação, especialmente no curso de Lazer e Turismo da EACH-USP. Faz breve revisão bibliográfica que ressalta os benefícios do estudo de meio como atividade motivadora na relação ensino-aprendizagem, e também como prática de observação direcionada por conceitos previamente apresentados em sala de aula. $\mathrm{O}$ texto ainda discorre sobre alguns requisitos importantes na elaboração de uma viagem didática, como, por exemplo, a realizada a Curitiba/PR durante a disciplina Turismos e Transportes. Por fim, mostra ainda depoimentos de alguns dos participantes.
\end{abstract}

Palavras-chave: Curitiba; Lazer e Turismo; Viagem Didática.

\begin{abstract}
The report shows the advantages of using fieldwork as a pedagogical practice in undergraduate courses, mainly in the EACH-USP Leisure and Tourism course. It presents a bibliographic review that highlights the benefits of the study of both as a motivating activity in the teaching-learning relationship as well as in the observation practice guided by concepts previously presented in the classroom. It discusses some important requirements in the elaboration of a didactic trip, reporting the trip to Curitiba/PR during the discipline Tourism and Transportation. It also shows testimonials from some of the participants.
\end{abstract}

Keywords: Curitiba; Leisure and Tourism; Didactic Trip.

\section{Introdução}

O presente relato teve como inspiração o pôster apresentado no $1^{\circ}$ Congresso de Graduação da Universidade de São Paulo, realizado em maio de 2015, em que procurei demonstrar a pertinência do trabalho de campo em determinadas situações da relação ensino-aprendizagem, especialmente na área de formação de profissionais de Lazer e Turismo (LZT), curso de graduação da Escola de Artes, Giências e Humanidades da Universidade de São Paulo (EACH-USP). Entre as práticas pedagógicas usuais no curso, destaca-se o trabalho de campo, momento em que se privilegia o contato direto do discente com a realidade, tanto como uma extensão da sala de aula quanto para a realização de pesquisa científica. Naquela oportunidade, foi apresentada em forma de pôster uma saída a campo no Museu dos Transportes Gaetano Ferolla (São Paulo/SP).

O campo é o laboratório para quem prepara profissionais que lidarão com o lazer e o turismo. Nas três disciplinas que ministrei no curso de LZT da EACH-USP, dei continuidade às práticas de viagens e visitas, assim como mestres de outras áreas do conhecimento fazem uso de um laboratório. Minha formação em Geografia certamente contribui muito para esse método de trabalho com os alunos da graduação. E o curso de LZT recebe essa prática de braços abertos. Os demais docentes do curso também adotam as viagens didáticas e visitas técnicas constantemente. De janeiro de 2015 a julho de 2016, houve várias experiências no laboratório 
"mundo real" que eu poderia relatar. Escolhi para este momento a viagem didática a Curitiba/PR, realizada entre os dias 12 e 16 de junho de 2015 , que concentrou conteúdos correlatos à disciplina Turismos e Transportes, de caráter teórico e prático.

\section{Revisão da Literatura}

Os trabalhos de campo, também denominados estudos do meio (PONTUSCHKA, 2001), podem ocorrer em qualquer ambiente, visto que se objetiva a prática de observação direcionada por conceitos previamente estudados em sala de aula (VENTURI, 2011). Essa prática de ensino apresenta-se como uma vivência de situações previstas teoricamente (VENTURI, 2011). Assim, ela deve ser previamente elaborada, de forma a tornar-se não só uma estratégia motivadora na relação ensino-aprendizagem (SANTOS \& TUNES, 2001), como também reveladora do objeto de estudo ao discente (PONTUSCHKA, op. cit.).

Dificilmente seria possível contemplar todas as dinâmicas espaciais apenas na sala de aula. De acordo com Pontuschka et al. (2009), "o processo de descoberta diante de um meio qualquer, seja urbano, seja rural, pode aguçar a reflexão do aluno para produzir conhecimentos que não estão nos livros didáticos". Ou seja, por mais que o professor disponha de diferentes metodologias de ensino dentro da sala de aula, algumas conclusões somente são tiradas pelos alunos durante uma aula prática, realizada através do trabalho de campo.

\section{A Viagem Didática como Metodologia de Ensino}

A aula prática, como em qualquer laboratório, deve ser minuciosamente planejada. Dentro da sala de aula, o docente também planeja sua aula, mas, se ocorre alguma interferência, algum evento não planejado, ele consegue mudar o seu rumo e rapidamente corrigir algo não programado. No campo, como lidar com as intempéries, trânsito ou outros infortúnios que podem comprometer o cronograma previamente estruturado?

Nossa viagem a Curitiba foi meticulosamente programada pelo coordenador do curso, Prof. Dr.
Antonio Carlos Sarti, e por mim, e contamos ainda com a ativa participação de alguns alunos (Bruna Simões, Renata Kazys, Vanessa Fugimoto), monitores (Amanda Cabral e Fillipe Soares Romano), além da companhia da professora Cynthia Correa na viagem. A Universidade contribuiu assumindo todos os custos de transporte, hospedagem e boa parte da alimentação. $\mathrm{O}$ trabalho em equipe e o financiamento foram decisivos para o sucesso da viagem.

Foi elaborado um manual de campo com o roteiro e horários de toda a programação, textos informativos, mapas e tabela para anotação de dados, entre outras atividades que foram realizadas durante a viagem. Estas compreendiam desde a observação e descrição, algo simples, porém bastante eficaz no processo de reconhecimento do espaço vivenciado, até a realização de entrevistas não estruturadas com os usuários dos meios e terminais de transporte utilizados. O manual deveria ser entregue preenchido no final da viagem, e foi um dos instrumentos de avaliação do semestre.

Com o objetivo de proporcionar experiências práticas de aprendizagem por meio de vivências relacionadas aos meios de transporte, a viagem a Curitiba possibilitou o contato com as modalidades de transportes que estruturam a oferta turística a partir dessa cidade. Foram utilizados os modais aéreo, no trajeto São Paulo - Curitiba - São Paulo; rodoviário, no receptivo rodoviário e traslados, bem como no uso do sistema de transportes coletivo local e da linha turística da cidade; ferroviário, com a experiência do trem turístico Curitiba - $\mathrm{Pa}-$ ranaguá; e, por fim, hidroviário, no deslocamento de barco entre Pontal do Sul e Ilha do Mel, no litoral paranaense. Cabe lembrar que boa parte dos estudantes nunca havia viajado de avião, nem mesmo de barco ou trem turístico.

O modal aéreo foi reservado pelo departamento de compras da EACH-USP. Já parte do receptivo rodoviário e a viagem no trem turístico foram contratadas a partir de uma agência de turismo local pelos professores, discentes e monitores envolvidos na programação. Além do roteiro de barco, também contratado pelos monitores, uma 
visita técnica a um renomado restaurante local e à Arena do Clube Atlético Paranaense (CAP) também foi reservada pelos monitores.

No último dia, os alunos fizeram roteiros em grupos utilizando-se da Linha Turismo, sistema hop on/hop off ${ }^{1}$, que proporcionou a visitação a diversos pontos turísticos da cidade.

\section{Resultados e Discussões}

O campo proporcionou o contato dos estudantes com as realidades do mercado de transporte e turismo por meio de atividades de estudo e pesquisa in loco, relacionadas com a análise da infraestrutura e dos serviços voltados ao atendimento de turistas. Os discentes ainda tiveram contato com responsáveis pelo setor de transporte, pelos meios e pelos locais visitados, a fim de discutirem as possibilidades, os problemas, as tendências de cada setor. Efetivamente, ocorreu a interação do aprendizado teórico com a experiência prática.

No primeiro dia da viagem, o clima chuvoso e frio atrapalhou ligeiramente os planos: uma caminhada no bairro Santa Felicidade teve de ser encurtada, e alguns alunos desistiram da visita à Arena CAP, optando por retornar ao hotel. Porém, conseguir unanimidade quando se está com um grupo de 89 alunos nem sempre é tão fácil. Foi possível contemporizar poucos atrasos em algumas saídas, e praticamente tudo ocorreu conforme o planejado. Ressaltamos a importância do manual de campo, de guias disponibilizados pelo contrato com uma agência de turismo local, de refeições previamente agendadas, enfim, de toda uma programação visando a que os alunos aproveitassem ao máximo todas as atividades.

Além do manual preenchido com as atividades, no retorno às aulas os grupos apresentaram seminários a partir dessa experiência, como forma de avaliação.

\section{Depoimentos: Impacto no Ensino de Graduação}

Compartilhamos depoimentos de alguns participantes da viagem didática, estudantes do curso de LZT, para melhor ilustrar os reflexos dessa metodologia no modo de pensar e agir dos alunos:
Acho que a nossa viagem didática [...] ajudou a elucidar conceitos que vemos dentro da academia. Não só no que se refere aos transportes, mas aos outros aspectos do turismo e lazer também. [...] $\mathrm{Eu}$ amei a viagem e acredito que, se houvesse mais experiências parecidas nos quatro anos de graduação, nossa bagagem intelectual seria muito maior; é muito mais fácil entender as dificuldades e oportunidades do turismo na prática.

Foi certamente uma das melhores experiências da graduação. Possibilitou contemplar pessoalmente grande parte dos modais estudados em aula. Especialmente em Curitiba, onde o transporte é um modelo, a experiência não poderia ter sido mais positiva. Além de termos contato com outras áreas do Turismo [...]. Certamente foi uma experiência que agregou muito a todos, seja pessoal, acadêmica ou culturalmente.

Na viagem técnica para Curitiba foi possível ter a experiência de poder vivenciar o que aprendemos em sala. A cidade é modelo no transporte público rodoviário, além de abrigar o trem turístico mais conhecido do país. Muitos dos modais utilizados durante a viagem (trem, barco, avião) foram utilizados pela primeira vez por mim, o que me agradou e proporcionou uma viagem mais especial $[\ldots]$.

Em um curso de Lazer e Turismo, uma viagem técnica pode ser considerada muito importante para que tenhamos uma vivência real do que é estudado ao longo do curso. Na disciplina de Turismos e Transporte, fomos a Curitiba e pudemos [...] conhecer uma cidade turística e aprender na prática [...], pudemos descobrir como funciona a excelente malha de transporte público da cidade. Foi importante também, ao meu olhar, o roteiro básico de visitação, assim, nós alunos poderíamos seguir os planos de trabalho e conhecer melhor o território de estudo.

O roteiro básico de visitação mencionado é o manual de campo, comentado nos itens anteriores. 


\section{Considerações Finais}

A imersão dos estudantes do curso de LZT da EACH-USP no universo real de sua futura prática profissional constituiu-se em uma experiência privilegiada que somente o campo pode proporcionar. Apenas a exposição do assunto em sala de aula certamente não teria o mesmo efeito. A partir de Curitiba, houve um extenso programa de visitas e estudos envolvendo os modais de transporte. A viagem didática certamente fez a diferença.

É, pois, necessário que a universidade continue investindo nas viagens didáticas e que a academia compreenda tratar-se do nosso laboratório, que precisa ser usado para a continuidade da primazia do curso de LZT.

\section{Nota}

1 Sistema que possibilita ao passageiro desembarcar em determinado ponto de visitação e depois embarcar em um próximo ônibus do sistema ou da linha.

\section{Referências Bibliográficas}

PONTUSCHKA, N. "São Paulo: A Cidade Educadora". In: CARLOS, Ana Fani A. \& OLIVEIRA, Ariovaldo U. (orgs.). Geografias de São Paulo. São Paulo: Contexto, 2001, vol. 1, pp. 382-387.

; PAGANELLI, T. I. \& CACETE, N. H. Para Ensinar e Aprender Geografia. São Paulo: Cortez, 2009.

SANTOS, C. \& TUNES, R. H. Geografia Escolar: Construções e Desconstruções. São Paulo, Nege/Autores, 2001.

VENTURI, L. A. B. Geografia. Práticas de Campo, Laboratório e Sala de Aula. São Paulo. Sarandi: 2011.

Publicado em 30/06/2017. 